IZA DP No. 4299

Productivity Growth and the Phillips Curve:

A Reassessment of the US Experience

Marika Karanassou

Hector Sala

July 2009 


\title{
Productivity Growth and the Phillips Curve: A Reassessment of the US Experience
}

\author{
Marika Karanassou \\ Queen Mary, University of London \\ and IZA \\ Hector Sala \\ Universitat Autònoma de Barcelona \\ and IZA
}
Discussion Paper No. 4299
July 2009

IZA
P.O. Box 7240
53072 Bonn
Germany

Phone: +49-228-3894-0

Fax: +49-228-3894-180

E-mail: iza@iza.org

\begin{abstract}
Any opinions expressed here are those of the author(s) and not those of IZA. Research published in this series may include views on policy, but the institute itself takes no institutional policy positions.

The Institute for the Study of Labor (IZA) in Bonn is a local and virtual international research center and a place of communication between science, politics and business. IZA is an independent nonprofit organization supported by Deutsche Post Foundation. The center is associated with the University of Bonn and offers a stimulating research environment through its international network, workshops and conferences, data service, project support, research visits and doctoral program. IZA engages in (i) original and internationally competitive research in all fields of labor economics, (ii) development of policy concepts, and (iii) dissemination of research results and concepts to the interested public.
\end{abstract}

IZA Discussion Papers often represent preliminary work and are circulated to encourage discussion. Citation of such a paper should account for its provisional character. A revised version may be available directly from the author. 


\section{ABSTRACT}

\section{Productivity Growth and the Phillips Curve: A Reassessment of the US Experience ${ }^{*}$}

In this paper we analyse a new Phillips curve (NPC) model and demonstrate that (i) frictional growth, i.e. the interplay of wage-staggering and money growth, generates a nonvertical NPC in the long-run, and (ii) the Phillips curve (PC) shifts with productivity growth. On this basis we estimate a dynamic system of macrolabour equations to evaluate the slope of the $P C$ and explain the evolution of inflation and unemployment in the US from 1970 to 2006. Since our empirical methodology relies heavily on impulse response functions, it represents a synthesis of the traditional structural modelling and (structural) vector autoregressions (VARs). We find that the PC is downward-sloping with a slope of -3.58 in the long-run. Furthermore, during the stagflating 70 s, the productivity slowdown contributed substantially to the increases in both unemployment and inflation, while the monetary expansion was quite ineffective and led mainly to higher inflation. Finally, the monetary expansion and productivity speedup of the roaring 90 s were both responsible for the significant lowering of the unemployment rate.

JEL Classification: E24, E31

Keywords: new Phillips curve, frictional growth, productivity growth, stagflating seventies, roaring nineties, impulse response functions

Corresponding author:

Hector Sala

Departament d'Economia Aplicada

Universitat Autònoma de Barcelona

08193 Bellaterra

Spain

E-mail: hector.sala@uab.es

\footnotetext{
* This paper was completed while Hector Sala was visiting the University of New South Wales School of Economics (Sydney, Australia). Their warm hospitality is gratefully acknowledged. Hector Sala is grateful to the Spanish Ministry of Education and Science for financial support through grant SEJ200614849/ECON and the mobility program 'Jose Castillejo'.
} 


\section{Introduction}

The purpose of this work is to measure the effects of money and productivity growth on the evolution of inflation and unemployment and evaluate the slope of the Phillips curve during two distinct and entirely different periods in the recent US history: the stagflating seventies and the roaring nineties. ${ }^{1}$ Our research addresses two central questions. To what extent have monetary expansions/contractions real effects on the economy? How does productivity growth affect the inflation-unemployment relationship? ${ }^{2}$ Our answers crucially depend on frictional growth, a phenomenon that encapsulates the interplay of frictions (due to timecontingent staggered nominal contracts and other labour market adjustment costs) and growth (of money supply and productivity) in a dynamic system of equations.

Despite the very poor performance of the Phillips curve (PC) during the 70s (and the $90 \mathrm{~s})$, rumours of the death of the PC proved to be premature, while the surrounding debate did instead heat up. ${ }^{3}$ Indeed, the rapid inflation and high unemployment rates witnessed in the 70 s (on the one hand) and the low and stable values of inflation and unemployment that characterised the 90s (on the other) - see Figure 1 - contradicted the PC predictions. The literature has generally addressed such contradictions by relating the shifts of the expectations-augmented PC to (i) movements of the natural rate of unemployment (NRU), and (ii) changes in the productivity growth. Both avenues are in line with the conventional wisdom of a short-run inflation-unemployment tradeoff and a NRU consistent with a vertical long-run Phillips curve.

Figure 1. Inflation and unemployment in the US

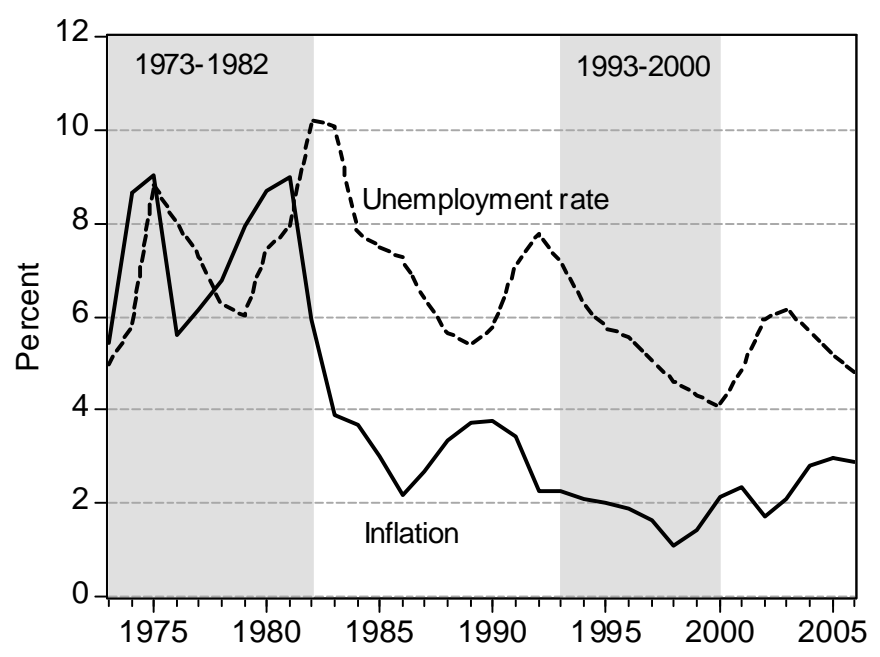

\footnotetext{
${ }^{1}$ For the fabulous performance of the US economy during the 90s see the insightful inside stories of Blinder and Yellen (2002), and Stiglitz (2003).

${ }^{2}$ There has been a revived interest in the inflation-unemployment tradeoff in the recent literature. See, among others, Akerlof, Dickens and Perry (2000), Ball (1999), Dolado, López-Salido and Vega (2000), Fisher and Seater (1993), Karanassou, Sala and Snower (2005, 2008), and Ribba (2007).

${ }^{3}$ See, for example, the 'After the Phillips curve' 1978 conference by the Federal Reserve Bank of Boston, and 'The Phillips Curve is Alive and Well' by Fuhrer (1995).
} 
The orthodox view that there is no long-run relationship between inflation and unemployment has been substantiated in recent years by the new Phillips curve (NPC), the current paradigm in monetary economics. The NPC model is a structural dynamic system comprising a price staggering equation that depends on "demand", an equation that relates the demand side of the model with prices, and an equation describing the policy rule. According to Mishkin (2007a, p. 1), the absence of a long-run inflation-unemployment tradeoff is one of "six ideas that are now accepted by monetary authorities and governments in almost all countries of the world."

However, the view that the long-run NPC is vertical relies on the implausible assumption of a zero discount rate. When the discount rate is positive, there is substantial inflation undershooting and the NPC is downward-sloping in the long-run (see Karanassou and Snower, 2008). This result is a manifestation of the interplay of nominal staggering and money growth, called frictional growth by Karanassou, Sala, and Snower (2005, 2008). It is important to stress that although lags and growth are the necessary conditions for frictional growth, a positive (albeit small) discount rate is what triggers it. This is because a positive discount rate implies that a larger weight is attached to the backward- than the forwardlooking component of the wage/price contract underlying the NPC. In other words, the current price is influenced more by its past level than its future one, and thus, as money growth increases, the increasing price level falls behind the increasing money supply and the resulting increase in real money balances lowers unemployment.

The orthodoxy of a vertical long-run PC has compartmentalised the macro-labour literature into one branch examining the (real) driving forces of unemployment, and another one modelling inflation dynamics. In sharp contrast, the finding of a long-run inflationunemployment tradeoff suggests the development of an all-encompassing empirical framework that can jointly explain the evolution of unemployment and inflation, and evaluate Phillips curve tradeoffs. Our contribution is to use such a holistic framework: a chain reaction theory (CRT) model of real and nominal dynamic equations with growing variables (or subject to permanent shocks) and spillover effects. ${ }^{4}$ The spillover effects arise when shocks to a specific equation feed through the macro-labour system, where "shocks" refer to changes in the exogenous variables.

Frictional growth is the key feature of the CRT economic viewpoint, and, as such, it distinguishes the CRT from the influential NRU and hysteresis frameworks. The interplay of lags and growth has two major implications for a macro-labour model. First, it implies that there is a long-run relationship between inflation and unemployment. Therefore, while

\footnotetext{
${ }^{4}$ This framework of analysis was originally developed by M. Karanassou and D. J. Snower for the labour market. See Karanassou, Sala and Snower (2009) for an overview of the various PC models, the singleequation unemployment rate models of the structuralist theory, and the CRT labour market models.
} 
the CRT and NRU are structural models, both aiming at identifying the driving forces of unemployment, the CRT has also the capacity of explaining the determinants of inflation. On the other hand, the hysteresis viewpoint merely offers a statistical representation of the unemployment rate process that focuses on the path dependency of unemployment (see, for example, Jaeger and Parkinson, 1994).

Second, frictional growth implies that the short and long runs are interdependent. At the other end of the spectrum, the NRU and hysteresis models decompose unemployment into a long-run component (natural rate) and a short-run (cyclical) component, but while the NRU assumes that the two components evolve independently of each other, hysteresis postulates that cyclical variations of unemployment propagate to its natural rate. Generally, nonhysteretic behaviour characterises a model where temporary shocks do not have permanent effects and so the rate of unemployment converges in the long-run to a value that does not depend on its initial conditions. The NRU hypothesis refers to this long-run value as the natural rate, estimates it as the steady-state, and asserts that actual unemployment tracks its natural rate very well. This is in sharp contrast with the CRT viewpoint, according to which the long-run is the sum of the steady-state (frictionless) rate and a frictional growth term due to the dynamics of the model and the nonzero long-run growth rates of the exogenous variables.

Acknowledging these two implications of frictional growth, the CRT modelling approach aims at evaluating the driving forces of inflation and unemployment by measuring the contributions of the exogenous variables to their trajectories.

Another novelty of this paper is that it relates its empirical model with the New Phillips Curve framework of analysis. Past accounts of the decaying seventies and roaring nineties have mainly relied on the traditional backward looking Phillips curve/NAIRU models. For the OECD countries, Grubb, Jackman and Layard (1982) explain the seventies' stagflation through a fall in the feasible growth of real wages due to the oil price shocks and the sharp fall in the growth rate of productivity. Ihrig and Márquez (2004), also for the OECD countries, argue that the declines in inflation in the nineties have no single cause. However, taking a very long-run perspective of the UK economy, Hatton (2007) finds that productivity growth matters for the NAIRU. The role played by the acceleration in labour productivity is also found to be central in the US. This is precisely the focus of Ball and Moffit (2002), who document a favourable Phillips curve shift due to the productivity speedup. Along these lines, Blinder and Yellen (2002) argue that the rise in productivity growth is a key supply shock. Despite this is also acknowledged by Staiger, Stock and Watson (2002), they attribute the explanation of a decreasing NAIRU to factors other than productivity acceleration.

Unlike the above studies, this paper offers an analytical illustration of a new Phillips curve (NPC) model with two salient features: it yields a long-run inflation-unemployment tradeoff, and the long-run Phillips curve shifts with productivity growth. The slope of the 
long-run Phillips curve is related to inflation persistence and unemployment persistence in the aftermath of monetary shocks. Whereas the standard NPC (downward-sloping in the short-run and vertical in the long-run) has recognized difficulties in accounting for inflation persistence and often implies implausible impulse-response functions (IRFs), our frictional growth NPC (downward-sloping in the short, medium and long-run) can generate inflation persistence and realistic IRFs for inflation and unemployment.

On the basis of such analytical framework we develop an empirical model to assess the impact of money and productivity growth on inflation and unemployment in the seventies and the nineties. We find that: (i) although the effects of the productivity slowdown in the 70s (i.e. higher inflation and unemployment) were reversed by the productivity speedup of the 90s, this reversion was not symmetric, and (ii) the Phillips curve was flatter in the roaring nineties than in the stagflating seventies. These results support the view that the Phillips curve moves in response to changes in productivity growth.

The rest of the paper is organised as follows. Section 2 analyses a NPC model with productivity, derives its closed-form rational expectation solution, and demonstrates the implications of the phenomenon of frictional growth . Section 3 estimates a holistic model for the US. In Section 4 this model is used to derive the slope of the long-run Phillips curve. Section 5 examines the contributions of money and productivity growth to the trajectories of inflation and unemployment in the seventies and nineties. Section 6 concludes.

\section{Analysis of a New (Keynesian) Phillips Curve Model}

\subsection{Wage-Staggering}

The staggered wage contracts proposed by Phelps (1978) and Taylor (1979, 1980) paved the way for the new Phillips curve by accommodating monetarist and rational expectations elements in the wage-price setting. Calvo's (1983) particularly popular model of timecontingent nominal contracts is commonly used as a convenient algebraic shorthand for the Taylor model. ${ }^{5}$

The pioneering contribution of wage/price staggering was that it strengthened the case against the view that the dynamic nature of the unemployment rate is merely a statistical one - if one could observe and include in the model all the relevant exogenous variables, lagged unemployment terms would simply become statistically insignificant. It is now widely understood that in a standard macro model with rational expectations, wage/price staggering alone induces unemployment to depend on its own lags.

In its simplest form, wage staggering assumes that nominal wages are fixed for two

\footnotetext{
${ }^{5}$ Goodfriend and King (1997, p. 254) show that under intertemporal optimisation, and with low inflation, constant elasticity of demand and small variations in adjustment patterns, Calvo's setup broadly resembles that of Taylor.
} 
periods and there are two contracts that are evenly staggered. The contract wage depends on past and expected future contract wages, as well as excess demand:

$$
W_{t}=\alpha W_{t-1}+(1-\alpha) E_{t} W_{t+1}+\gamma x_{t}
$$

where the contract wage $W_{t}$ is set at the beginning of period $t$ for periods $t$ and $t+1$, $x_{t}$ denotes excess demand, and $E_{t}(\cdot)$ is the expectation of the variable conditional upon information available at time $t$. (All variables are in logs; for expositional ease, and without loss of generality, we ignore supply shocks and future excess demand.) The demand sensitivity parameter $\gamma$ describes how strongly wages are influenced by demand, and $\alpha$ is the backward-looking weight.

It is important to stress that the only restriction that needs to be imposed on the backward- and forward-looking weights is that they add up to unity - they do not have to be equal to one another. The fundamental principle of finance that "a dollar today worths more than a dollar tomorrow", implies that the coefficient $\alpha$ is a discounting parameter equal to $\frac{1+r}{2+r}$, where $r$ is the discount rate. This can be seen as follows. The one-period ahead wage $\left(W_{t+1}\right)$ needs to be discounted by the factor $\beta=\frac{1}{1+r}$ so that it is used in the wage-staggering equation (1) alongside with the wage set in the previous period $\left(W_{t-1}\right)$ that still applies in period $t$. Given that wage staggering requires that the wage set at period $t$ is a weighted average of past and future wages and their respective weights add up to $1+\beta$, we need to rescale them by the parameter $\alpha=\frac{1}{1+\beta}$ so that they add up to unity. It then follows that time discounting and a nonzero interest rate (so that $\beta<1$ and $\alpha>1 / 2$ ) give rise to an asymmetry in wage determination: the current wage $W_{t}$ is affected more strongly by the past wage $W_{t-1}$ than the future expected wage $E_{t} W_{t+1}$. This may be called the intertemporal weighting asymmetry.

This result is also well known from the microfoundations of Taylor-type contract equations under time discounting. Recent contributions to the microfoundations of wage-price setting under time-contingent staggered nominal contracts have shown that when agents discount the future (viz., they have a positive rate of time preference), then the backwardlooking variables are weighted more heavily than the forward-looking ones, i.e. $\alpha>1 / 2 .{ }^{6}$

The wage-staggering equation (1) can be reparameterised to give the following wage new (Keynesian) Phillips curve, NPC: ${ }^{7}$

$$
\Delta W_{t}=\beta E_{t} \Delta W_{t+1}+\gamma(1+\beta) x_{t},
$$

where $\Delta$ is the first difference operator, and, as discussed above, the discount factor $\beta=$

\footnotetext{
${ }^{6}$ Ascari (1998), Graham and Snower (2008), Helpman and Leiderman (1990), Huang and Liu (2002), and others.

${ }^{7}$ This can be obtained by adding and subtracting on the left-hand side of (1) the terms $W_{t-1}$ and $(1-\alpha) W_{t}$, and using $\beta$ to denote $\frac{1-\alpha}{\alpha}$.
} 
$\frac{1-\alpha}{\alpha}=\frac{1}{1+r}$. The NPC model (2) is the wage inflation variant of the sticky-price workhorse NPC model (see, among others, Roberts, 1995, Galí and Gertler, 1999, and Mankiw and Reis, 2002), and it explains current wage inflation $\Delta W_{t}$ by expected wage inflation one period ahead and a "forcing" variable $x_{t}$ that captures excess demand. Usually, the forcing variable stands for the (log) output gap, unemployment rate, or $(\log )$ wage share.

Since the realised discount factor is close to unity, the conventional wisdom disregards intertemporal weighting asymmetry as mere technicality with no economic significance. In stark contrast, we show below that the intertemporal weighting asymmetry has important implications for the long-run slope of the Phillips curve as it gives rise to the phenomenon of frictional growth, i.e. the interplay of wage staggering (frictions) and permanent monetary changes (growth).

\subsection{Frictional Growth}

We start by noting that the use of the term "forcing" variable in the NPC models suggests the exogeneity of $x_{t}$. However, in the context of all reasonable macro models of the Phillips curve, $x_{t}$ is not exogenous. ${ }^{8}$ Rather, wage inflation $\Delta W_{t}$ and the real variable $x_{t}$ are both endogenous responding to economic policy changes. In the standard macro models excess demand depends on real money balances. We thus augment the wage-staggering model (1) with the following simple demand-side equation:

$$
x_{t}=M_{t}-P_{t}
$$

where $M_{t}$ denotes the log of money supply. Note that the above relationship is positive when $x_{t}$ denotes the output gap or the wage share, and negative when $x_{t}$ denotes unemployment. Under the plausible assumption of a zero long-run growth rate of excess demand (i.e. $\Delta x^{L R}=0$ ), the above demand equation implies money neutrality, since inflation is equal to money growth in the long-run:

$$
\pi^{L R}=\mu^{L R}
$$

where $\mu^{L R}=\Delta M^{L R}$. Note that this is in line with the long-run neutrality definition given by Fisher and Seater (1993, p. 405).

Let us rewrite the wage staggering equation (1) as follows: ${ }^{9}$

$$
\left(\frac{\gamma}{1-\alpha}\right) P_{t}=\left(\frac{\gamma}{1-\alpha}\right) M_{t}+E_{t} \Delta W_{t+1}-\left(\frac{\alpha}{1-\alpha}\right) \Delta W_{t} .
$$

\footnotetext{
${ }^{8}$ From an econometric perspective, Bårdsen, Jansen and Nymoen (2004) evaluate the NPC and emphasize the importance of modelling a system that includes the forcing variable as well as the rate of inflation.

${ }^{9}$ Substitute (3) in (1):

$$
W_{t}=\alpha W_{t-1}+(1-\alpha) E_{t} W_{t+1}+\gamma M_{t}-\gamma P_{t}
$$
}


Therefore, assuming that wage inflation stabilises in the long-run so that $\Delta W_{t}=E_{t} \Delta W_{t+1}=$ $\Delta W^{L R}$, we have that the long-run solution of a dynamic equation equals its steady-state and frictional growth.

$$
\begin{aligned}
\left(\frac{\gamma}{1-\alpha}\right) P^{L R} & =\left(\frac{\gamma}{1-\alpha}\right) M^{L R}+\left(1-\frac{\alpha}{1-\alpha}\right) \Delta W^{L R} \Rightarrow \\
\underbrace{P^{L R}}_{\text {long-run }} & =\underbrace{M^{L R}}_{\text {steady-state }}+\underbrace{\left(\frac{1-2 \alpha}{\gamma}\right) \Delta W^{L R}}_{\text {frictional growth }} .
\end{aligned}
$$

Naturally, if there is no growth in the model, the long-run reduces to the steady-state. It is also important to observe that frictional growth does not arise when wage staggering is symmetric (i.e. $\alpha=1 / 2$ in (1)). In the context of NPC models, the necessary and sufficient conditions for the existence of frictional growth can be summarised as follows. While nominal frictions (due to wage/price staggering), and growth (e.g. permanent shocks like a change in the inflation target) are the necessary conditions, the intertemporal weighting asymmetry (due to a positive discount rate) is the sufficient one.

\subsection{The NPC with Productivity}

Assuming constant returns to labour in the production function, we close the model with the following markup equation for the (log) price level:

$$
P_{t}=\frac{1}{2}\left(W_{t}+W_{t-1}\right)-p r_{t}
$$

where $p r_{t}$ is the log of labour productivity. It is important to note that $W_{t}$ is the contract wage, while the average wage is given by $\frac{1}{2}\left(W_{t}+W_{t-1}\right)$. In the standard Taylor setup "the aggregate price level is determined by a simple proportional markup over the average wage" [Taylor (1980), p. 6].

Inserting the tautology $W_{t-1} \equiv W_{t}-\Delta W_{t}$ in (7) yields $P_{t}=W_{t}-p r_{t}-\Delta W_{t}$. The first difference of this price markup equation specifies the relation between inflation $\left(\pi_{t} \equiv \Delta P_{t}\right)$, wage inflation $\left(\Delta W_{t}\right)$, and productivity growth $\left(\theta_{t} \equiv \Delta p r_{t}\right)$. In the long-run, assuming that the growth rate of wages stabilises, we obtain the neoclassical benchmark in which

and reparameterise to obtain

$$
W_{t}=E_{t} W_{t+1}+\left(\frac{\gamma}{1-\alpha}\right) M_{t}-\left(\frac{\gamma}{1-\alpha}\right) P_{t}-\left(\frac{\alpha}{1-\alpha}\right) \Delta W_{t}
$$

Next, substitution in the above of the tautology $W_{t+1} \equiv W_{t}+\Delta W_{t+1}$ yields equation (5)

$$
W_{t}=W_{t}+E_{t} \Delta W_{t+1}+\left(\frac{\gamma}{1-\alpha}\right) M_{t}-\left(\frac{\gamma}{1-\alpha}\right) P_{t}-\left(\frac{\alpha}{1-\alpha}\right) \Delta W_{t}
$$


productivity growth equals real wage growth:

$$
\Delta W^{L R}=\pi^{L R}+\theta^{L R},
$$

where the superscript ${ }^{L R}$ denotes the long-run. This is "a standard equation for price inflation" in Ball and Moffit (2002, equation (4)). Substituting (4) into (8) shows that

$$
\Delta W^{L R}=\mu^{L R}+\theta^{L R} .
$$

From equations (6) and (9) it is easy to see that the phenomenon of frictional growth does not arise when (i) money and productivity growth rates are zero in the long-run, or (ii) there is intertemporal weighting symmetry $(\beta=1 \Longleftrightarrow \alpha=1 / 2)$.

Substitution of the price markup (7) and demand (3) equations into the wage-setting equation (1) yields:

$$
W_{t}=\phi_{1} W_{t-1}+\phi_{2} E_{t} W_{t+1}+\frac{2 \gamma}{2+\gamma}\left(M_{t}+p r_{t}\right)
$$

where $\phi_{1}=\frac{2 \alpha-\gamma}{2+\gamma}, \phi_{2}=\frac{2(1-\alpha)}{2+\gamma}$.

To derive the rational expectations solution of the above NPC model, it is convenient to write the second-order difference equation of the contract wage (10) as

$$
W_{t}=\lambda_{1} W_{t-1}+\frac{\gamma}{\lambda_{2}(1-\alpha)} \sum_{j=0}^{\infty}\left(\frac{1}{\lambda_{2}}\right)^{j} E_{t}\left(M_{t+j}+p r_{t+j}\right),
$$

where $\lambda_{1,2}=\frac{1 \mp \sqrt{1-4 \phi_{1} \phi_{2}}}{2 \phi_{2}}, 0<\lambda_{1}<1$, and $\lambda_{2}>1$. $^{10}$

According to equation (11) the contract wage depends on its lagged value and expected future money supplies and productivity levels. Obviously, different stochastic processes for $M_{t}$ and $p r_{t}$ give rise to different wage dynamics. Thus, the closed form rational expectations solution of the NPC model can be obtained once we specify stochastic processes for the

${ }^{10}$ To derive eq. (11) multiply equation (10) by the backshift operator $B$ and use

$$
1-\frac{1}{\phi_{2}} B+\frac{\phi_{1}}{\phi_{2}} B^{2}=\left(1-\lambda_{1} B\right)\left(1-\lambda_{2} B\right)
$$

to obtain:

$$
\begin{aligned}
&\left(1-\lambda_{1} B\right)\left(1-\lambda_{2} B\right) W_{t}=\frac{-\gamma B E_{t}\left(M_{t}+p r_{t}\right)}{(1-\alpha)} \Rightarrow \\
&\left(1-\lambda_{1} B\right) W_{t}=\frac{\gamma}{(1-\alpha)}\left[\frac{-B E_{t}\left(M_{t}+p r_{t}\right)}{\left(1-\lambda_{2} B\right)}\right] \\
&=\frac{\gamma}{(1-\alpha)}\left[\frac{E_{t}\left(M_{t}+p r_{t}\right)}{\lambda_{2}\left(1-\lambda_{2}^{-1} B^{-1}\right)}\right] .
\end{aligned}
$$


evolution of the money supply and productivity.

\subsection{Closed-form Solution with Rational Expectations}

Since the analysis of the long-run Phillips curve naturally requires that we consider the unemployment rates associated with different long-run inflation rates, we need to consider permanent shocks to money growth (corresponding, say, to permanent changes in the central bank's inflation target). For simplicity, let money growth $\left(\Delta M_{t} \equiv \mu_{t}\right)$ follow a random walk: ${ }^{11}$

$$
\mu_{t}=\mu_{t-1}+\varepsilon_{t}
$$

where $\varepsilon_{t}$ is a strict white noise error term. We assume that rational agents at time $t$ know the stochastic process generating money growth, and have information up to the shock $\varepsilon_{t}$, but do not know future realisations of the money growth shock. In this case a positive one-period unit shock $\left(\varepsilon_{t}=1, \varepsilon_{t+j}=0\right.$ for $\left.j>0\right)$ represents a permanent increase in money growth which, under money neutrality (4), leads to a unit increase in the long-run inflation rate.

Similarly, we model permanent shifts in productivity growth $\left(\Delta p r_{t} \equiv \theta_{t}\right)$, by assuming a random walk stochastic process:

$$
\theta_{t}=\theta_{t-1}+\epsilon_{t}
$$

where $\epsilon_{t}$ is another strict white noise error term.

By the wage equation (11) and the money and productivity stochastic processes (12)(13), we obtain the following contract wage dynamics:

$$
W_{t}=\lambda_{1} W_{t-1}+\left(1-\lambda_{1}\right)\left(M_{t}+p r_{t}\right)+\left(\frac{1-\lambda_{1}}{\lambda_{2}-1}\right)\left(\mu_{t}+\theta_{t}\right)
$$

or

$$
\left(1-\lambda_{1} B\right) W_{t}=\left(1-\lambda_{1}\right)\left(M_{t}+p r_{t}\right)+\left(\frac{1-\lambda_{1}}{\lambda_{2}-1}\right)\left(\mu_{t}+\theta_{t}\right),
$$

where $B$ is the backshift operator.

Substituting (14) into the price markup (7), and further algebraic manipulation yields

\footnotetext{
${ }^{11}$ The qualitative conclusions of this analysis do not hinge on the random walk assumption. Any money growth process involving a permanent change in the money growth (e.g. an $I(0)$ money growth process with a change in money growth regime, or a permanent change in the monetary authority's reaction function) would do. The random walk assumption simply offers an elegant way to capture an unanticipated monetary shift.
} 
the following dynamic specification for real money balances: ${ }^{12}$

$$
\left(1-\lambda_{1} B\right)\left(M_{t}-P_{t}\right)=\left(1-\lambda_{1}\right)\left(\frac{2 \alpha-1}{\gamma}\right)\left(\mu_{t}+\theta_{t}\right)+\frac{1}{2}\left(\frac{1-\lambda_{1}}{\lambda_{2}-1}\right)\left(\epsilon_{t}-\varepsilon_{t}\right) .
$$

Inserting the above in the demand equation (3) gives the closed form rational expectations dynamic specification of the unemployment rate, $u_{t}$ :

$$
u_{t}=\lambda_{1} u_{t-1}-\left(1-\lambda_{1}\right)\left(\frac{2 \alpha-1}{\gamma}\right)\left(\mu_{t}+\theta_{t}\right)-\frac{1}{2}\left(\frac{1-\lambda_{1}}{\lambda_{2}-1}\right)\left(\epsilon_{t}-\varepsilon_{t}\right) \text {. }
$$

\subsection{The Long-run Phillips Curve}

It is easy to see that the long-run solution of the unemployment dynamics equation (16) is given by

$$
u^{L R}=-\left(\frac{2 \alpha-1}{\gamma}\right)\left(\mu^{L R}+\theta^{L R}\right) .
$$

Substituting (4) in the above, and rearranging, we derive the long-run NPC:

$$
\pi^{L R}=-\left(\frac{\gamma}{2 \alpha-1}\right) u^{L R}-\theta^{L R}
$$

According to the above equation, the long-run NPC is downward sloping and shifts to the left with higher productivity growth rates. As explained in Section 2.2 this is due to frictional growth, the interplay of lags with growing variables that arises when the backward- and forward-looking elements of wage-setting are asymmetric as a result of a positive discount rate. Observe that when the discount rate is zero, and so there is intertemporal weighting symmetry $\left(\alpha=\frac{1}{2}\right)$, there is no inflation-unemployment tradeoff and the Phillips curve is vertical in the long-run. Although some recent studies (e.g. Mankiw and Reis, 2002) also analysed the NPC by specifying an equation for the "forcing" variable and deriving the closed-form rational expectations solution of the model, they obtained a vertical Phillips curve due to the assumption of a zero discount rate.

\footnotetext{
${ }^{12}$ The price dynamics equation is given by

$$
\begin{aligned}
\left(1-\lambda_{1} B\right) P_{t}= & \frac{1}{2}\left(1-\lambda_{1}\right)\left(M_{t}+p r_{t}\right)+\frac{1}{2}\left(\frac{1-\lambda_{1}}{\lambda_{2}-1}\right)\left(\mu_{t}+\theta_{t}\right)-\left(1-\lambda_{1} B\right) p r_{t} \\
& +\frac{1}{2}\left(1-\lambda_{1}\right)\left(M_{t-1}+p r_{t-1}\right)+\frac{1}{2}\left(\frac{1-\lambda_{1}}{\lambda_{2}-1}\right)\left(\mu_{t-1}+\theta_{t-1}\right) .
\end{aligned}
$$
}

It can also be shown that

$$
\frac{1}{2}\left(1+\lambda_{1}\right)-\left(\frac{1-\lambda_{1}}{\lambda_{2}-1}\right)=\left(1-\lambda_{1}\right)\left(\frac{2 \alpha-1}{\gamma}\right)
$$




\section{Empirical Methodology of the Chain Reaction Theory}

In what follows we use the chain reaction theory (CRT) methodology to develop an empirical model of the US economy that can jointly explain the evolution of unemployment and inflation, and measure the interplay of their dynamics. CRT models, like vector autoregressions (VARs) and traditional simultaneous equations (SE), build upon dynamic multi-equation systems. Whereas the set of exogenous variables and the lag structure are allowed to differ among the individual equations of CRT and SE models, VAR equations share an identical set of regressors. In addition, unlike VARs, contemporaneous values of the endogenous variables may appear as explanatory variables in CRT and SE models.

The individualistic nature of the CRT and SE regressions has the advantage of making them appealing to our economic reasoning. However, the simultaneity element of the CRT and SE systems gives rise to spillovers which can affect both the size and the sign of the slopes or elasticities. Compared to SE models, the value added of the CRT methodology is that the impulse response functions (IRFs) are a focal point in the analysis of its models. As we explain in the next section, IRFs can be used to assess the economic plausibility of the model. The 'chain reaction' epithet flags the crucial role of IRFs in CRT model building. Although IRFs are also at the core of VAR modelling, the two methodologies are sharply differentiated by the way they depict an impulse: in the VAR system shocks (impulses) arise from its error terms, while in the CRT system "shocks" refer to the actual changes in the exogenous variables.

We should emphasise that, whereas the SE and VAR models aim at bridging (what they regard as) the compartmentalised areas of "theoretical" analysis and applied work, CRT modelling is driven by the bidirectional feedback between theory (or a prior viewpoint) and evidence. The "holistic" nature of the CRT methodology implies that its equations can neither be characterised as atheoretical, like the VAR ones, nor can they be simply regarded as loose interpretations of economic theory, like those of the traditional SE models. ${ }^{13}$

Our CRT framework comprises a "nominal block" with price and wage equations, a "real block" with equations for the unemployment rate and capital accumulation, and is characterised by spillover effects. Note that our model advances the Karanassou, Sala and Snower (2005) model by endogenising capital accumulation, since it had a key role in explaining unemployment. ${ }^{14}$ Because capital accumulation reacts to changes in productivity growth, the model allows us to evaluate the role played by productivity growth in shaping the trajectories of inflation and unemployment via both the nominal and real channels of our model. Although a justification of the importance of capital accumulation to the un-

\footnotetext{
${ }^{13}$ See Karanassou and Sala (2009) for a detailed analysis of the various methodological issues surrounding vector autoregressions, traditional simultaneous equations, and chain reactions.

${ }^{14}$ Furthermore, in our earlier works we have demonstrated that one of the salient features of the CRT is that capital stock is a major driving force of the unemployment rate both in the short and long runs (see Karanassou, Sala and Salvador, 2008; and Karanassou, Sala and Snower, 2009).
} 
employment trajectory is beyond the scope of this paper, our empirical model contributes to the controversial and hotly debated issue of the capital-unemployment relationship. It is important to point out that our empirical model also represents an extensive modification of the standard NPC model analysed in Section 2. In particular, our empirical model augments the set of explanatory variables used in the wage-setting equation (1) and demand-side equation (3), adds a price-staggering equation in the system, and endogenises capital accumulation. Therefore a one-to-one correspondence between the parameters of the analytical and empirical models should not be expected. ${ }^{15}$

Our econometric approach is based on the autoregressive distributed lag (ARDL) methodology of Pesaran and Shin (1999), and Pesaran, Shin and Smith (2001). These studies propose a bounds testing procedure for the analysis of level relationships, which is an alternative to the standard cointegration techniques of the Phillips-Hansen semi-parametric fully-modified OLS procedure, and the Johansen maximum likelihood method. The major advantage of the ARDL methodology is that it yields consistent short- and long-run estimates, and can be reliably used in small samples for hypothesis testing irrespective of whether the regressors are I(1) or I(0). Naturally, since an ARDL equation can be reparameterised in error-correction form, its long-run solution can be interpreted as the cointegrating vector of the variables included in the equation. ${ }^{16}$

We apply the ARDL methodology to estimate each of the four equations in our model - price, nominal wage, unemployment rate, and capital accumulation - and determine their dynamic specifications by the optimal lag-length algorithm of the Schwarz information criterion. The selected equations are dynamically stable (i.e., the roots of their autoregressive polynomial lie outside the unit circle), and pass the standard diagnostic tests at conventional significance levels. See Table A in the Appendix for the misspecification and structural stability tests. To take into account the potential endogeneity and cross equation correlation, we estimate our equations as a system using three stages least squares (3SLS). In Sections 4 and 5 below, we use our empirical macro-labour model to identify (i) the short- and longrun inflation-unemployment tradeoffs, and (ii) the contributions of money and productivity growth to the evolution of the unemployment and inflation rates.

We should emphasise that, although the wage and price equations depend only on lags (and not leads), they derive from staggering equations that contain backward- and forwardlooking components. As we showed in Section 2.4, the rational expectations solution of wage/price staggering models translates the expected future values of the variables into their current and past values.

\footnotetext{
${ }^{15}$ We should note that, in order to derive analytical (rather than numerical) solutions, the NPC model in Section 2 needs to be closed (i.e. as many equations as variables). In contrast, our estimated model is not a closed one.

${ }^{16}$ For further details regarding the implementation of the ARDL methodology see, among others, Karanassou, Sala and Salvador (2008). To save space we do not report the unit root and LM tests which show that our ARDL results are in line with those obtained from the Johansen procedure.
} 


\subsection{Evaluating Macro Models: "Global" versus "Local" Elasticities}

One main advantage of the empirical CRT models, which is shared with the traditional structural macroeconometric models, is the economic intuition and plausibility that accompanies each of the estimated equations. In other words, a CRT model has the capacity of explaining economic developments and measuring the contribution of the various exogenous variables to the evolution of the endogenous ones. However, due to the plethora of feedback mechanisms built-in the multi-equation systems of macro models, the elasticity of an endogenous variable with respect to an exogenous one may not be adequately captured in the respective individual equation. We refer to the individual equation elasticity as the "local" one and we distinguish it from the "global" elasticity which takes into account all the relevant spillover effects in the multi-equation system. ${ }^{17}$

The global elasticities are obtained by the impulse response function (IRF) of an endogenous variable with respect to a one-off unit change (shock) in an exogenous variable. In stable dynamic models, the effects of a shock persist after the shock is over and gradually dissipate with the passage of time. For a one-off unit change (impulse) occurring at period $t$, the IRF gives the responses through time $\left(R_{t+j}, j>0\right)$ of the endogenous variable to this impulse. ${ }^{18}$ In particular, (i) the short-run global elasticity is given by the contemporaneous response (i.e. the initial value of the IRF function, $R_{t}$ ), and (ii) the long-run global elasticity is given by the cumulative sum of responses, $\sum_{j=0}^{\infty} R_{t+j}$. Observe that if we define persistence $(\sigma)$ as the sum of all responses in the aftermath of the shock, $\sigma \equiv \sum_{j=1}^{\infty} R_{t+j}$, we can decompose the long-run elasticity $\left(\varepsilon_{L R}\right)$ into the short-run elasticity $\left(\varepsilon_{S R}\right)$ and persistence: $\varepsilon_{L R}=\varepsilon_{S R}+\sigma$.

An important drawback of the traditional structural macroeconometric methodology of simultaneous equations (SE) was the disregard of the IRFs of the model. The elasticities (slopes) of the individual equations can be quite misleading regarding the influence of the exogenous variables on the endogenous ones, since the spillovers in the system can substantially affect both the size and the sign of the elasticities (slopes). On these grounds, vector autoregressions (VARs), ${ }^{19}$ with their exclusive focus on the IRFs of the system offered a statistically robust (albeit economically sterile) alternative. VARs were heavily criticized

\footnotetext{
${ }^{17}$ Note that the simultaneous equation literature refers to "direct" and "indirect" effects of the exogenous variables instead of "local" and "global" effects. The reason we choose the latter terminology is that indirect=global-direct, where direct=local. In other words, while the direct (local) effects can be obtained by mere inspection of the individual equation, the indirect effects are a function of the global ones.

${ }^{18}$ Note that the IRF can be obtained by the infinite moving average (IMA) representation of the endogenous variable with respect to an exogenous one. In turn, the IMA is derived by the univariate representation of the specific endogenous variable, i.e. an equation where its right-hand side comprises lagged dependent variables and exogeous ones.

${ }^{19}$ This macroeconomic framework was pioneered by Sims in 1980. See Stock and Watson (2001) for a brief and comprehensive tutorial.
} 
for their atheoretical (i.e. statistical rather than economic) nature. Structural vector autoregressions (SVARs) addressed this critique by replacing the atheoretical identification of the VAR equations with an economic structure of the error terms. ${ }^{20}$ In other words, the SVAR methodology uses economic theory to decide on the contemporaneous correlations among the variables - hence, the "structural" adjective. The models are adjusted until they give "reasonable" impulse response functions. Since the economic plausibility of the signs and magnitudes of the elasticities of the various exogenous variables serves to diagnose the model in hand, we believe that a crucial factor that led to the demise of the SE models, which were very popular in the past, was the lack of such a diagnosis.

Unlike the traditional SE models, the chain reaction theory emphasises the importance of the IRFs in its investigation and uses the global elasticities as a misspecification tool to diagnose the economic plausibility of the model. Thus, the CRT methodology can be viewed as a synthesis and improvisation of the traditional structural SE models and the (structural) VARs. A further advantage of the CRT framework is that shocks have a concrete economic interpretation as they represent the actual changes in the exogenous variables. It is also worth noting that the CRT analysis and empirical results do not depend on the ordering of the equations in the model.

\subsection{Data and Equations}

Our sample spans the 1970-2006 period with annual frequency, and is obtained from the IMF International Financial Statistics (oil prices) and the OECD Economic Outlook (rest of the variables). ${ }^{21}$ Table 1 gives the definitions of the endogenous and exogenous variables in our empirical model.

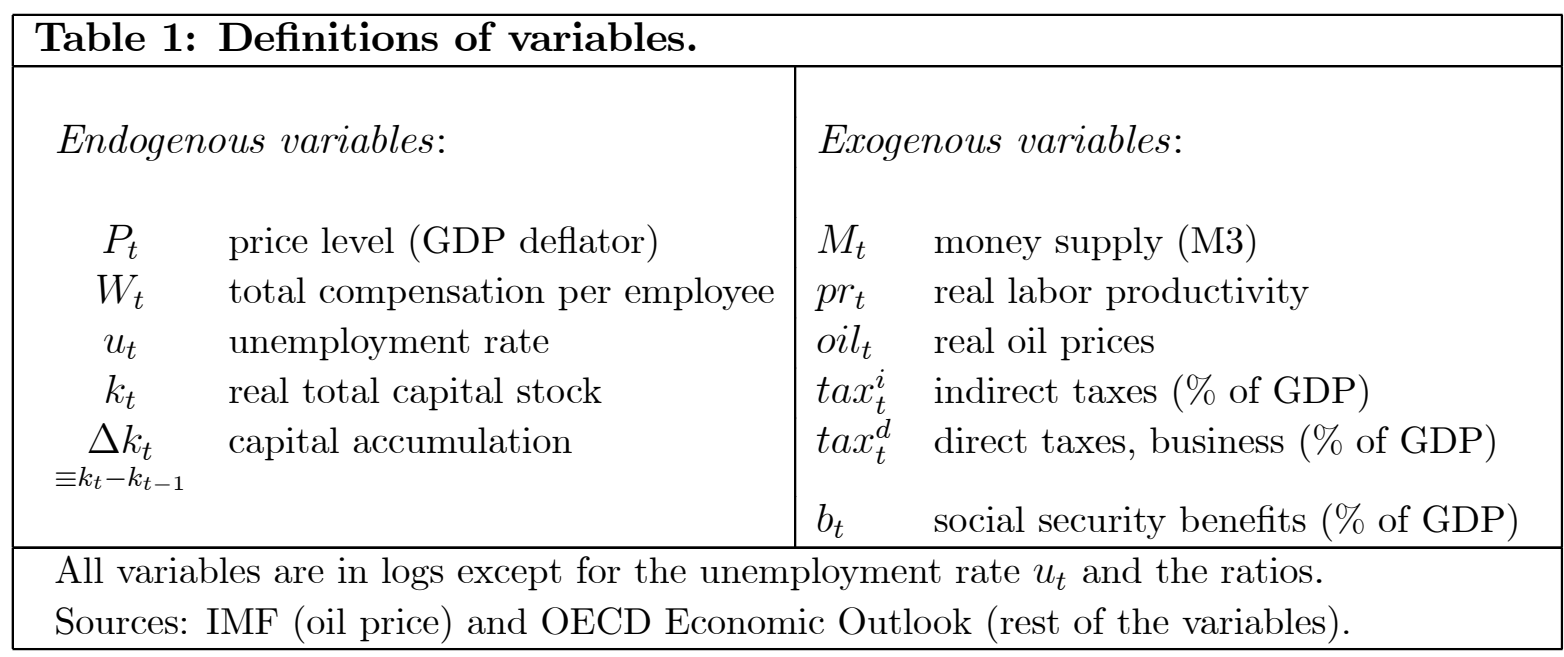

\footnotetext{
${ }^{20}$ See, among others, Leeper, Sims, and Zha (1996), Rudebusch (1998), Christiano, Eichenbaum, and Evans (1999, 2005), Raddatz and Rigobon (2003), Dedola and Lippi (2005), and Ribba (2007).

${ }^{21}$ The data provided by the OECD Economic Outlook have recently undergone important methodological changes (for example, the capital stock series, $k_{t}$, is the total one instead of the business sector one), and all data series start in 1970 instead of 1960.
} 


\subsection{Estimated Equations}

Table 2 displays the estimated CRT model for the US.

Prices are determined by nominal and real-side variables. As expected, price dynamics are influenced positively by nominal wages. Note that the hypothesis of money neutrality (no money illusion) cannot be rejected at conventional significance levels, i.e. the nominal equations are homogeneous of degree zero in the nominal variables. ${ }^{22}$ The real set of determinants include productivity, with an expected negative sign and a long-run elasticity close to unity, and oil prices, direct taxes on firms and indirect taxes, all of which put upward pressure on prices.

The nominal wage equation is also quite standard. Like prices, nominal wages are homogeneous of degree zero in all nominal variables. In this case the hypothesis of money neutrality implies that the equation can be reparameterised to specify real wages as a function of real money balances. These restrictions conform with the definition of money neutrality given in Section 2.2 and in Fisher and Seater (1993). The real driving forces of nominal wages are productivity and unemployment. Increases in productivity raise wages with a long-run elasticity of 0.73 , implying that not all productivity gains are translated into wage increases. In contrast, unemployment is inversely related with wages as it moderates their mark-up over prices.

We should note that, in the context of the macro-labour model in Table 2, the assumption of a unitary elasticity of real wages with respect to productivity is valid when the restriction holds in both the price and wage equations. Since the restriction does not hold in the wage equation, imposing it on the price equation alone has no value added for our empirical results.

The unemployment equation displays simple dynamics with a relatively low autoregressive parameter of 0.44 , which reflects the flexibility of the US labour market. Capital accumulation (measured by the growth rate of capital stock) and real money balances have a significant role in lowering unemployment. On the other hand, social security benefits and oil prices, as expected, put upward pressure on unemployment.

A key feature of our empirical study is that capital accumulation is endogenous, reacting to changes in productivity growth. In this way, productivity growth affects unemployment both via the price/wage dynamics and capital accumulation. Our findings are far from controversial: capital accumulation is influenced positively by productivity growth and negatively by real wages and unemployment. We should stress that, although a comprehensive explanation of the determinants of capital stock growth is beyond the scope of this paper, our simple dynamic specification accounts for $83 \%$ of the actual variation in capital accumulation.

\footnotetext{
${ }^{22}$ The $\chi^{2}$ Wald tests for the price and wage equations are 0.70 [0.403] and 3.62 [0.057], respectively, where p-values are in square brackets.
} 


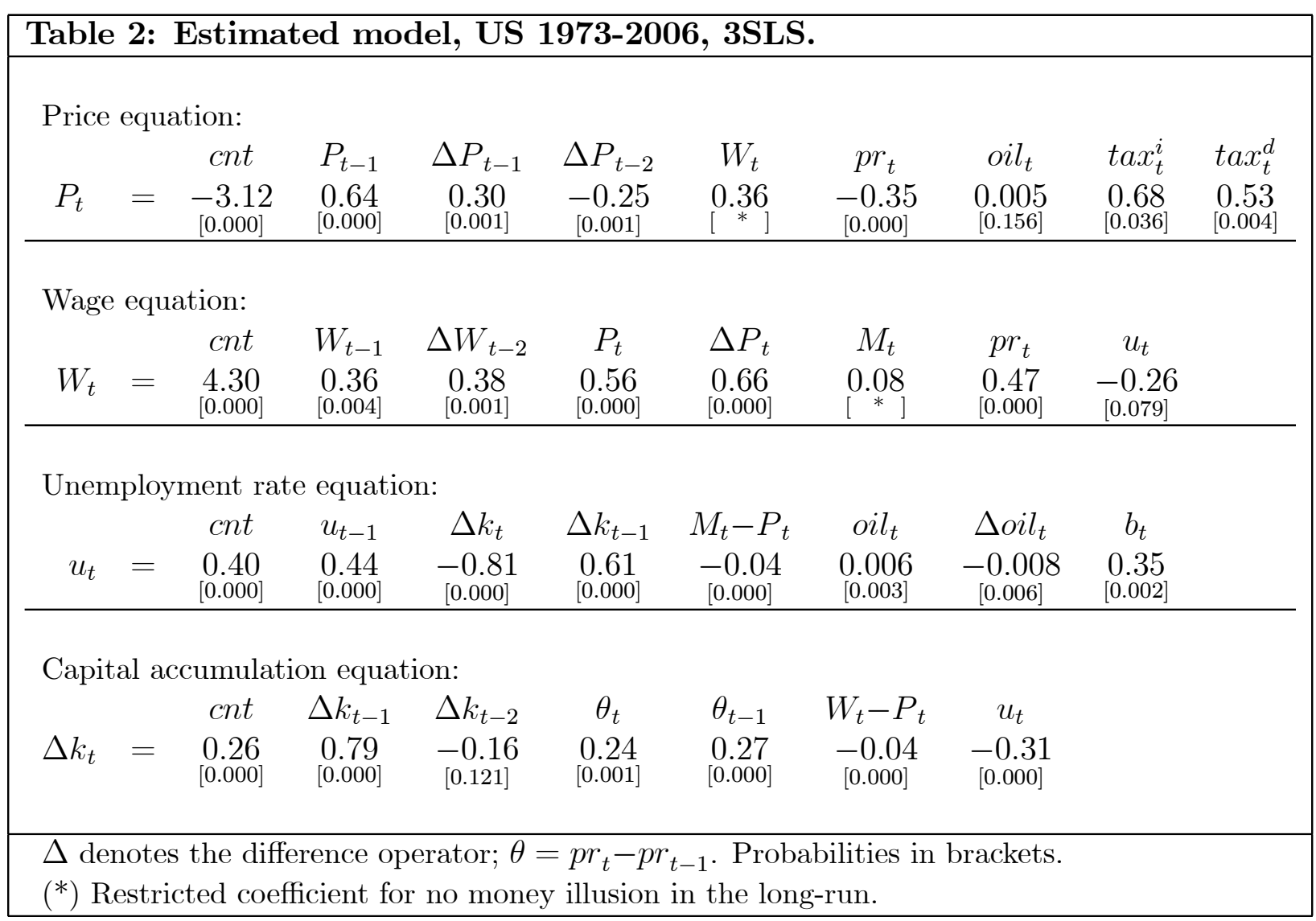

Figure 1 displays the actual and (interactive) fitted values of price inflation and unemployment. Observe that, notwithstanding the money neutrality restrictions, the mix of both nominal and real equations with numerous spillover effects, and the estimation of a pricelevel equation instead of an inflation one, our model tracks reasonably well the evolution of the unemployment and inflation rates since the first oil price shock.

Figure 2. Actual and fitted values

a. Inflation

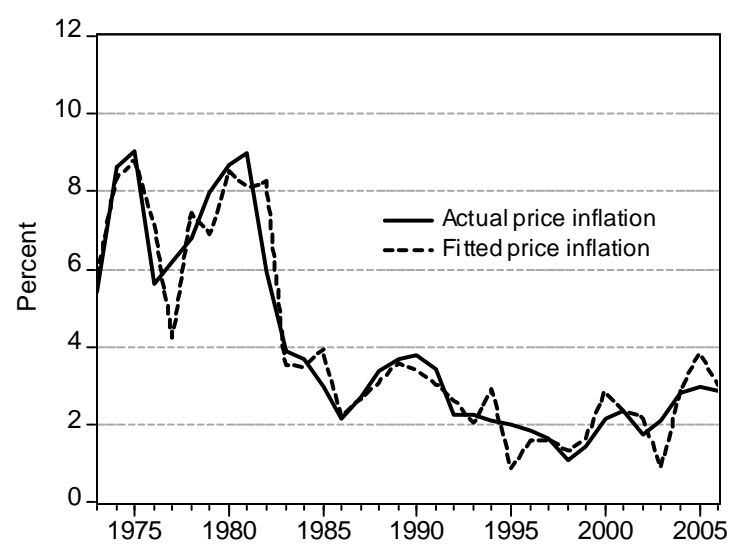

b. Une mployment

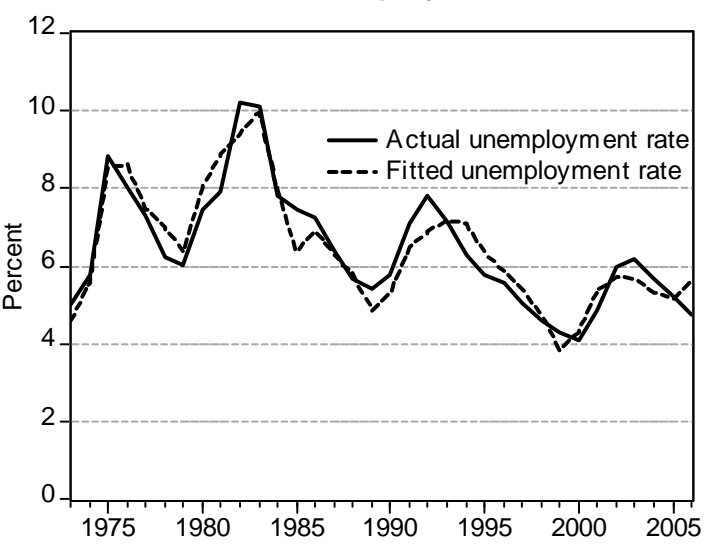




\subsection{Global Long-run Elasticities and Effects}

As we explained above, in dynamic multi-equation models with spillovers it is crucial that we measure the overall effects of the exogenous variables on the endogenous ones, i.e. the influence of a change in the exogenous variable once the feedback channels are operative. These effects are intimately related to what we call "global" elasticities, as opposed to what we describe as "local" elasticities which are commonly derived from the respective individual equations.

In dynamic models, the impulse response functions (IRFs) show how each of the exogenous variable influence the endogenous ones through time. In other words, the IRFs provide an elegant and comprehensive way to calculate the global elasticities which can then be used to judge the economic plausibility of the selected system of equations.

Table 3 presents the global long-run elasticities and effects of unemployment with respect to each of the exogenous variables in our chain reaction theory model. The first row of the table gives the elasticities and the size of the shock in parentheses. The latter simply reflects the actual "average" change in the respective exogenous variable and is commonly measured by the sample standard deviation of the series. ${ }^{23}$ The second row multiplies the long-run elasticity by the size of the shock and, thus, gives the long-run effect of each exogenous variable on the unemployment rate. The results in the table show that money and productivity growth have the expected overall negative influence on unemployment, while oil prices and the institutional variables (e.g. benefits and taxes) lead to higher unemployment. Observe that a $1 \%$ increase in money and productivity growth reduces the rate of unemployment by 0.28 and 0.64 of a percentage point, respectively. However, a more realistic picture can be obtained if, instead of assuming a unit size for all shocks, we proxy their actual size by the sample standard deviations of the relevant series. In this case, a one-off rise of $2.9 \%$ in money growth and $1.2 \%$ in productivity growth decrease the long-run unemployment rate by 0.81 and 0.75 of a percentage point, respectively.

\begin{tabular}{|c|c|c|c|c|c|c|}
\hline & $\mu$ & $\theta$ & oil & $\operatorname{tax} x^{i}$ & $\operatorname{tax}^{d}$ & $b$ \\
\hline $\begin{array}{l}\text { Long-run elasticity } \\
\text { (Size of the shock) }\end{array}$ & $\begin{array}{c}-0.279 \\
(0.029)\end{array}$ & $\begin{array}{c}-0.643 \\
(0.012)\end{array}$ & $\begin{array}{l}0.018 \\
(0.439)\end{array}$ & $\begin{array}{l}1.042 \\
(0.003)\end{array}$ & $\begin{array}{l}0.807 \\
(0.005)\end{array}$ & $\begin{array}{l}0.678 \\
(0.011)\end{array}$ \\
\hline Long-run effect & -0.813 & -0.752 & 0.791 & 0.350 & 0.417 & 0.768 \\
\hline
\end{tabular}

\footnotetext{
${ }^{23}$ Recall that under the assumption of normality, there is a $68.3 \%$ chance that the value of the variable is in the range of one standard deviation to the left and one standard deviation to the right of its mean. Furthermore, according to Chebyshev's rule, for all datasets the interval $\bar{x}-2 s$ to $\bar{x}+2 s$, where $\bar{x}$ is the sample mean and $s$ is the standard deviation, contains at least $75 \%$ of the data.
} 
Since the predictions of our empirical CRT model are quite plausible, in what follows we entrust it to evaluate Phillips curve tradeoffs and measure the contributions of money and productivity growth to the evolution of inflation and unemployment.

\section{The Long-run Phillips Curve}

The Phillips curve relationship essentially represents the comovements of inflation and unemployment which are caused by changes in the monetary conditions. In our analysis, we examine the Phillips curve by evaluating the time-varying responses of inflation and unemployment to a permanent shift in the money growth rate.

Generally, we regard money growth to be a better indicator of the monetary environment than the federal funds rate, since the former reflects not only the level of the yield curve (i.e. short-term interest rate), but also its slope (i.e. spread) and curvature (i.e. relative spread). Furthermore, Nelson (2007) stresses that "the intertwined positions that money growth pins down inflation in the long-run, and that the central bank cannot treat the nominal interest rate as an instrument in the long-run, have been supported by monetary economists who have also served as leading policy makers." ${ }^{24}$ In addition, Reynard (2007) documents the importance of monetary aggregates and, in sharp contrast, the inadequacy of short-term interest rates in modelling the evolution of inflation. Finally, Cooley and Hansen (1989), and Mankiw and Reis (2002), among others, assume that the monetary policy shock is the error in the time series representation of money growth.

We derive the slope of the Phillips curve at various time horizons as the ratio of the inflation and unemployment IRFs to a permanent monetary shock. In particular, we shock our empirical model with an unanticipated permanent shift in money growth, say from 0 to $10 \%$ at $t=0$, to our empirical model and simulate it until the variables stabilise in the longrun. Note that, due to the linearity of the system, the size of the shock and the evolution of all other exogenous variables do not affect the impulse response functions. ${ }^{25}$ Figure 3 a plots the inflation and unemployment IRFs, whereas Figure $3 \mathrm{~b}$ plots the time-varying slope of the Phillips curve. In line with stylised facts (see, for example, Mankiw 2001), the responses of both magnitudes are delayed and gradual and unemployment adjusts faster than inflation. Naturally, since our model satisfies the money neutrality restriction, inflation stabilises at $10 \%$ in the long-run. Furthermore, the shorter the time horizon, the flatter the slope of the PC is. The only controversial feature of the IRFs is that the unemployment effects of the monetary shock do not dissipate with the passage of time. In fact, unemployment decreases by 2.79 percentage points in the long-run, implying that the long-run slope of the PC is

\footnotetext{
${ }^{24}$ Bernanke, Goodhart, and Mishkin are among them.

${ }^{25}$ Since the residuals of our structural model are uncorrelated with changes in money growth, we are justified to assume that there are no other shocks to the model. Note that this is the counterpart of the standard assumption in vector autoregressions (VARs) of zero covariances between the structural innovations.
} 
$\frac{10}{-2.79}=-3.58$.

Figure 3. The Phillips curve slope in the US

a. Inflation and unemployment

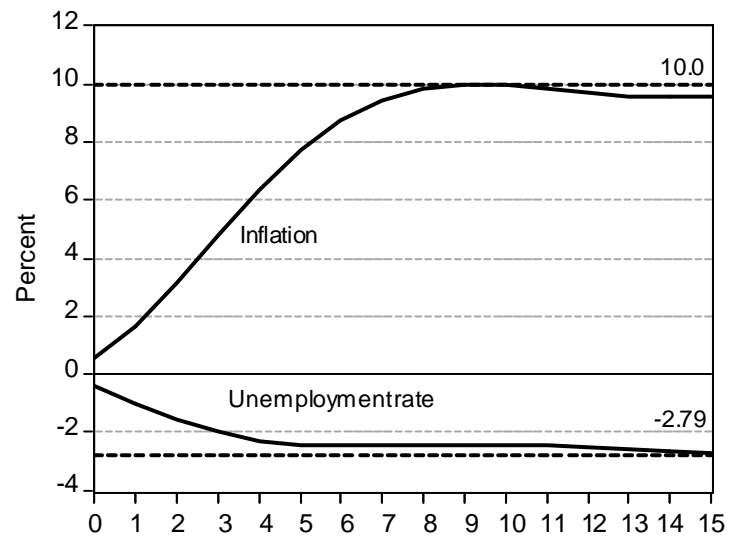

b. Short, medium and long-run slopes

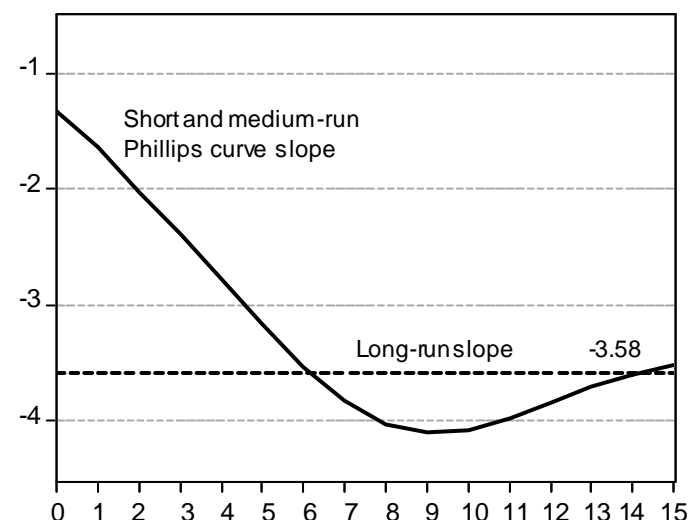

We should point out that a nonvertical PC does not imply unemployment hysteresis, since the derivation of the PC involves a permanent monetary shock (recall that hysteresis arises when a temporary shock has a permanent effect on unemployment). It is also worth pointing out that the finding of a long-run tradeoff supports the view of Stiglitz (2003, p. 44) that the choice of the appropriate inflation-unemployment mix should be a political decision, since there is not a single right answer.

\section{Contributions of Money and Productivity Growth}

In what follows we evaluate the role of money and productivity growth in shaping the trajectories of inflation and unemployment during the stagflating 1973-1982 period and the roaring nineties 1993-2000 period. To measure the contribution of each factor during the 1973-1982 (1993-2000) period we perform counterfactual simulations or, in Sims' jargon, 'innovation accounting'. In particular, each exogenous variable is fixed at its 1973 (1993) value over the 1973-1982 (1993-2000) period, while the rest of the exogenous variables follow their actual trajectories. The disparity between the actual and simulated series of inflation (unemployment) measures the dynamic contribution of the specific factor to the evolution of the inflation (unemployment) rate over that period.

Figures $4 \mathrm{a}$ and $4 \mathrm{~b}$ plot money growth and productivity growth, respectively. The dotted lines represent the values at which the series remain fixed during each period of interest in our simulations. Observe that while both periods witnessed a monetary expansion, they differed sharply in terms of productivity. The stagflating seventies were characterised by 
the infamous productivity slowdown which followed the high growth rates of the previous 30 years (the post World War II 'golden years'). The roaring nineties, in turn, were characterised by a productivity speedup which was associated with the New Economy (i.e., the extensive and intensive development of information and communication technologies) that ended abruptly in 2000-2001.

Figure 4. Money and productivity growth in the US

a. Money growth

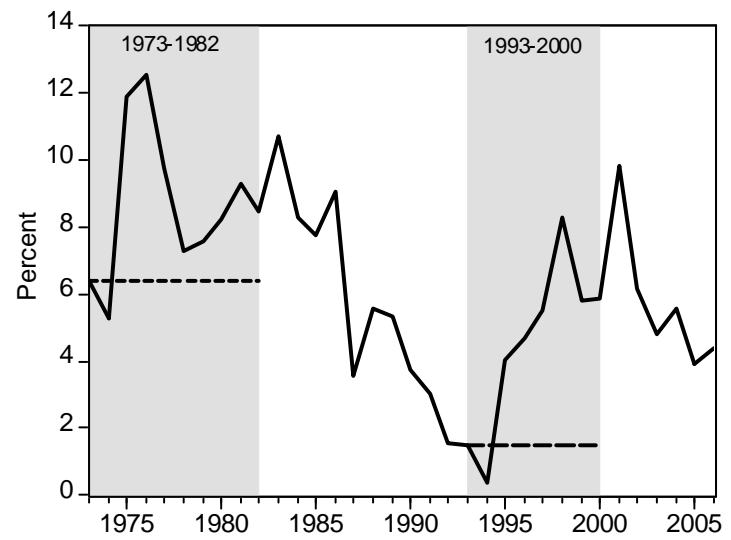

b. Productivity growth

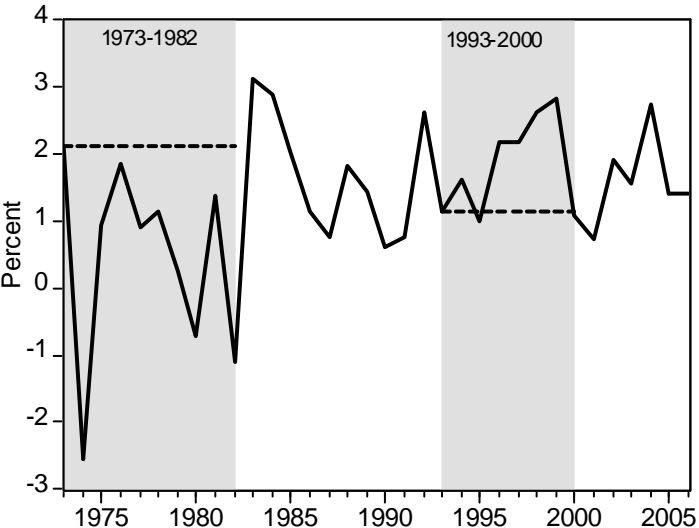

Figures 5a-b show that the monetary expansion of the seventies led to a substantial increase of 2.4 percentage points (pp hereafter) in inflation, and a rather negligible decrease in unemployment. ${ }^{26}$ Thus, our accounting analysis documents the ineffective monetary policy of the seventies which has been heavily criticised (see, among others, Romer and Romer, 2003).

Figure 5. Contributions of money growth in the seventies

a. Inflation

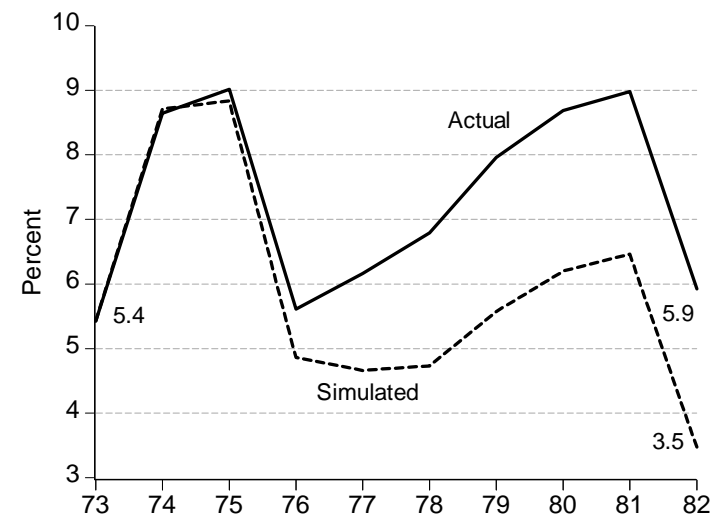

b. Unemployment

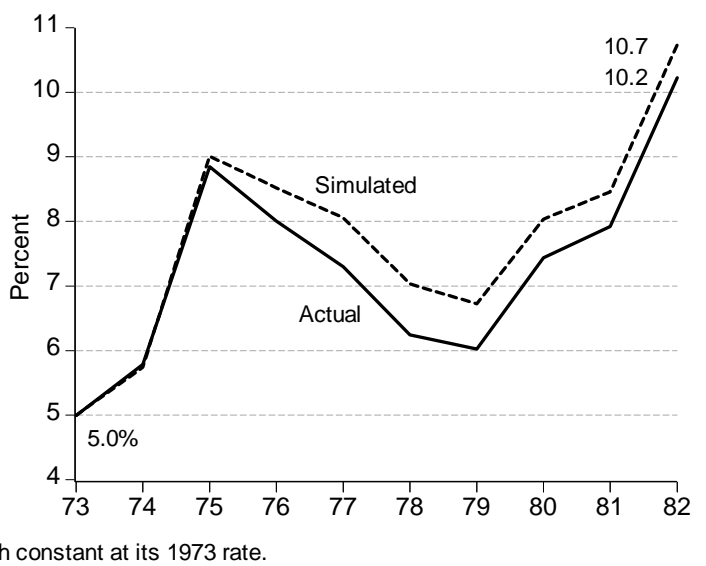

\footnotetext{
${ }^{26}$ Note that had money growth remained at its 1973 level, inflation would have been $3.5 \%$ in 1982 , as opposed to its actual value of $5.9 \%$. On the other hand, the unemployment rate would have been $10.2 \%$ instead of $10.7 \%$.
} 
Figure 6. Contributions of productivity growth in the seventies

a. Inflation

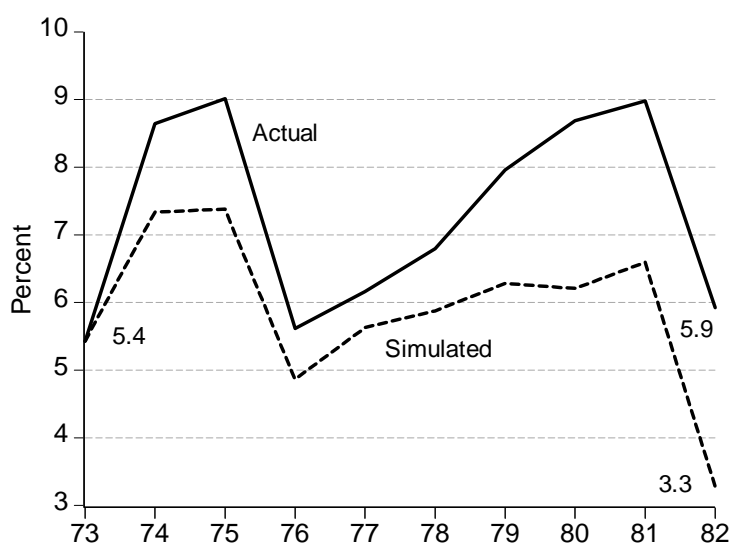

b. Unemployment

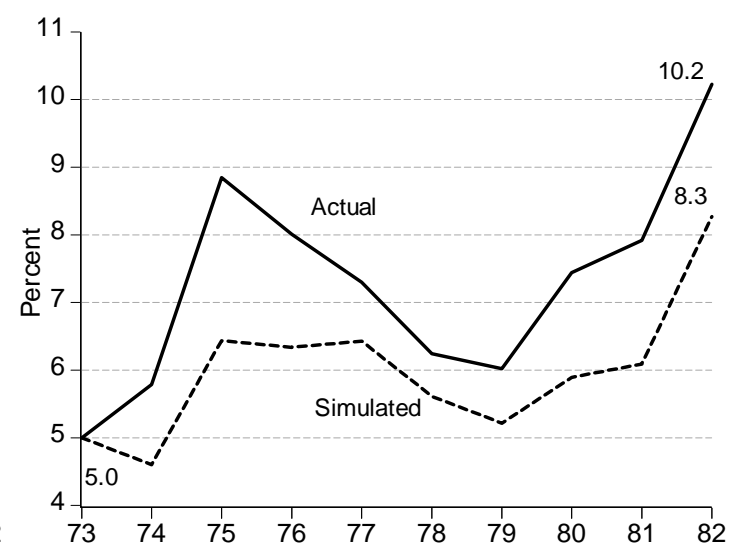

Note: Simulated series are computed by keeping productivity growth constant at its 1973 rate.

As shown in Figures 6a-b, the economic outlook of the seventies was further worsened by the strong adverse effects of the lower productivity growth rates. According to our accounting simulations, by 1982 , inflation was $2.6 \mathrm{pp}$ higher than it would have been in the absence of the decrease in productivity growth. Furthermore, the productivity slowdown was responsible for nearly forty percent of the 5 pp rise in unemployment during those years.

Figure 7. Contributions of money growth in the nineties

a. Inflation

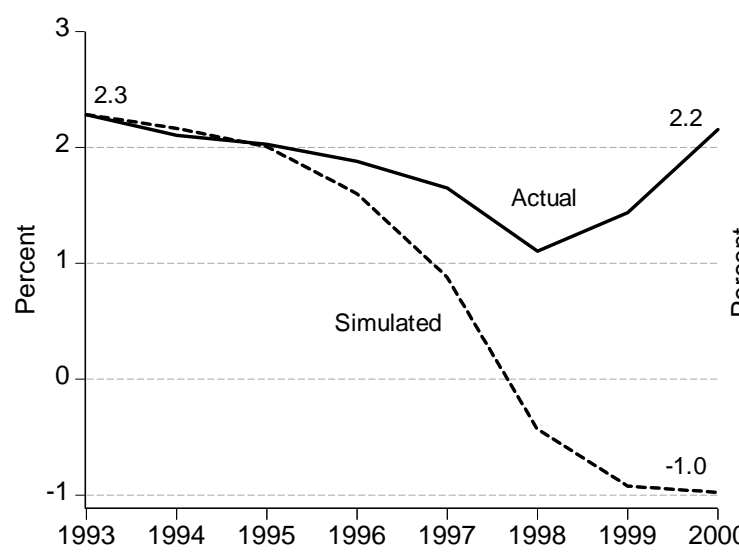

b. Unemployment

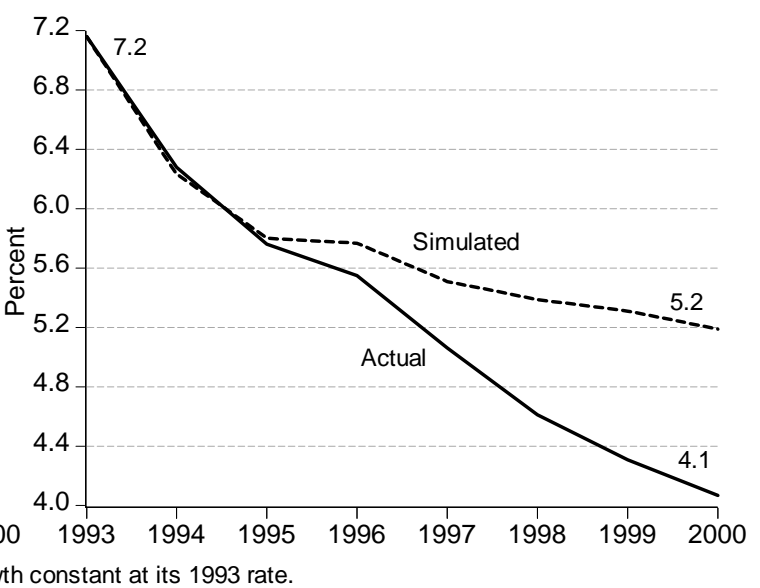


Regarding the roaring nineties, Figures 7a-b show that, whereas inflation would have been much lower had the monetary expansion not taken place, unemployment would have ended the decade $1.1 \mathrm{pp}$ higher than its actual value. Furthermore, the productivity speedup reduced inflation by $0.7 \mathrm{pp}$ and unemployment by 1 pp (see Figures 8a-b). In other words, the monetary expansion was responsible for one third of the overall 3 pp decrease in unemployment (from around 7\% in 1993 to 4\% in 2000), while the productivity speedup accounted for another one third of the fall in unemployment.

\section{Figure 8. Contributions of productivity growth in the nineties}

\section{a. Inflation}

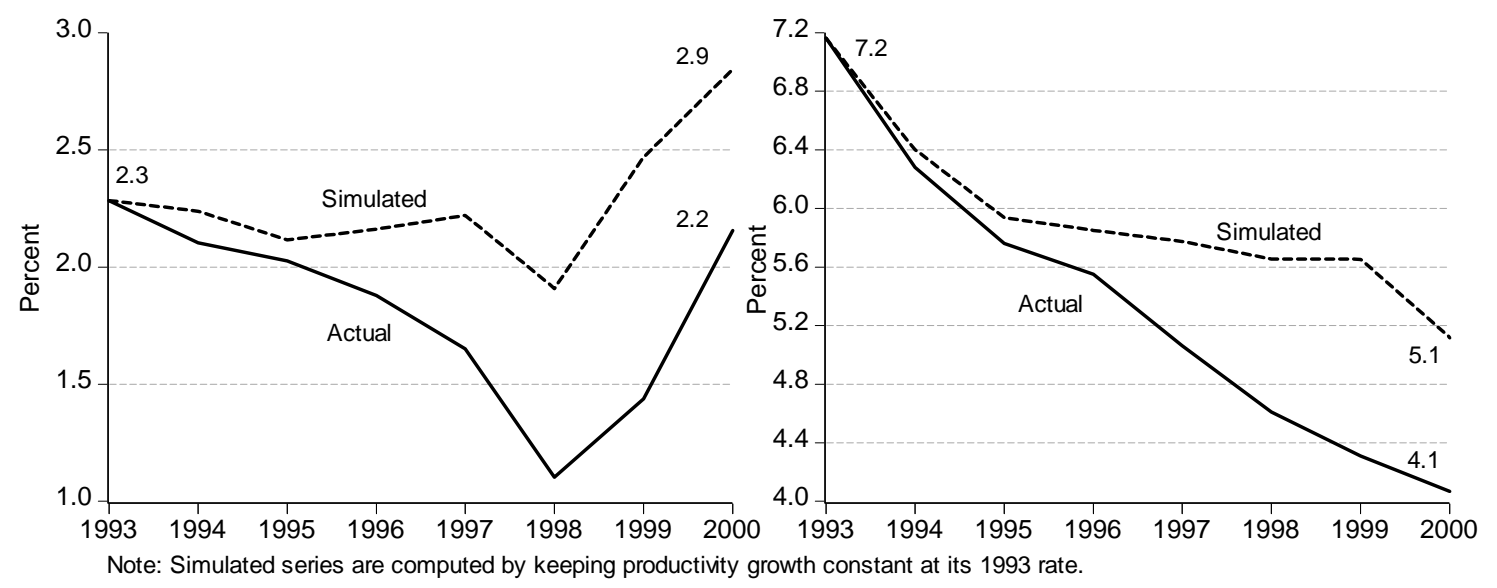

The above simulations, in line with Ball and Moffit (2002) and Blinder and Yellen (2002), indicate that the effects of the productivity slowdown in the 70s (i.e. higher inflation and unemployment) were reversed by the productivity speedup of the 90s. In particular, Blinder and Yellen (2002, p. 64) argue that "In the 1970s, an unrecognised productivity slowdown led to "excessive" wage settlements, more inflation and less employment. In the 1990s, an unrecognised productivity speedup had precisely the opposite effects."

However, this reversion was not symmetric. For a detailed comparison of the inflation and unemployment impacts in the 70s with those in the 90s, we standardise them by dividing with the respective changes in the money and productivity growth rates over the specific period. ${ }^{27}$ In standardised terms, we find that the impact of productivity growth on inflation was higher in the stagflating 70s than in the roaring 90s (inflation increased by $1.54 \mathrm{pp}$ in the $70 \mathrm{~s}$ and fell by $1.03 \mathrm{pp}$ in the $90 \mathrm{~s}$ ). On the other hand, unemployment was influenced more by the productivity speedup of the 90s than the productivity slowdown of the 70s (unemployment fell by $1.47 \mathrm{pp}$ in the $90 \mathrm{~s}$ and increased by $1.12 \mathrm{pp}$ in the $70 \mathrm{~s}$ ).

\footnotetext{
${ }^{27}$ Note that (i) the change in money growth is 2.26 pp from 1973 to 1982, and 3.02 pp from 1993 to 2000 , and (ii) the change in productivity growth is -1.69 pp over the $1973-1982$ period, and 0.68 pp over the 1993-2000 period.
} 
Finally, following a monetary expansion, the increase in inflation was approximately the same in both periods, while the reduction in unemployment was about 1.6 times higher in the $90 \mathrm{~s}$ than in the $70 \mathrm{~s}$ (unemployment fell by $0.36 \mathrm{pp}$ in the $90 \mathrm{~s}$ and $0.22 \mathrm{pp}$ in the $70 \mathrm{~s}$ ). Therefore, our analysis indicates that the Phillips curve was flatter in the roaring nineties than in the stagflating seventies and supports the view of Mishkin (2007b, p.7) that "...the evidence suggests that the Phillips curve has flattened."

\section{Conclusions}

In this paper we analysed a new Phillips (NPC) curve featuring productivity and showed that (i) frictional growth (arising from the interplay of wage-staggering and money growth) generates a long-run inflation-unemployment tradeoff, and (ii) the long-run Phillips curve shifts with productivity growth. We further showed that the long-run solution of the model is the sum of its steady-state and frictional growth. Generally, the phenomenon of frictional growth encapsulates the interplay of model dynamics and the nonzero long-run growth rates of the exogenous variables.

Acknowledging the above implications of frictional growth, we developed an empirical model which can jointly explain the evolution of unemployment and inflation. Our modelling approach, which we call the chain reaction theory (CRT) is "holistic" in the sense that it does not compartmentalise the analysis of the inflation and unemployment issues. In particular, our estimated model extends the standard NPC system of the wage-staggering and demand-side equations by augmenting the set of explanatory variables, adding a pricesetting equation in the system, and endogenising capital accumulation.

The predictions of our empirical model are strong and plausible. First, notwithstanding the money neutrality restrictions and the mix of both nominal and real equations with numerous spillover effects, our model tracks reasonably well the evolution of the unemployment and inflation rates. Second, as expected, we found that money and productivity growth reduce unemployment, while oil prices and the institutional variables (e.g. benefits and taxes) lead to higher unemployment. To ensure that we take full account of the dynamics and feedback channels in the model, we obtained the elasticities of unemployment with respect to each of the exogenous variables from the respective impulse response functions (IRFs).

In this context, we derived the time-varying slope of the PC over the 1973-2006 period as the ratio of the inflation and unemployment responses to a permanent shift in money growth. We found a downward-sloping Phillips curve with a long-run slope of -3.58. Furthermore, we evaluated the role of money and productivity growth in shaping the trajectories of inflation and unemployment during the stagflating 70s and the roaring nineties $90 \mathrm{~s}$.

Regarding the 70s, our accounting simulations showed that the monetary expansion produced a substantial increase in inflation and a rather negligible unemployment reduction, 
while the productivity slowdown increased both inflation and unemployment. The monetary expansion of the 90s put upward pressure on inflation and, unlike the 70s, significantly lowered unemployment. On the other hand, the productivity speedup of the 90s put downward pressure on inflation and substantially reduced unemployment. It is worth noting that the monetary expansion and productivity speedup of the 90s were each responsible for one third of the overall $3 \mathrm{pp}$ decrease in unemployment, while the productivity slowdown of the 70 s accounted for two fifths of the overall 5 pp increase in unemployment.

The policy implications of our work are twofold. First, the documented medium- and long-run inflation-unemployment tradeoffs question the validity of the natural rate of unemployment NRU hypothesis which is compatible with a vertical PC and, consequently, with the compartmentalised investigation of the determinants of inflation and unemployment. Second, beyond the widely recognised influence of institutional factors (such as benefits and taxes), money and productivity growth are crucial driving forces of unemployment.

\section{References}

[1] Akerlof, G.A., W.T. Dickens, and G. L. Perry (2000): "Near-rational wage and price setting and the long-run Phillips curve", Brookings Papers on Economic Activity, 1:2000, pp. 1-60.

[2] Ascari, G. (1998): "Superneutrality of money in staggered wage-setting models", Macroeconomic Dynamics, 2, pp. 383-400.

[3] Ball, L. (1999): "Aggregate demand and long-run unemployment", Brooking Papers on Economic Activity, 2:1999, pp. 189-251.

[4] Ball, L. and R. Moffit (2002): "Productivity growth and the Phillips curve" in A. Krueger and R. Solow (eds.), The Roaring Nineties: Can Full Employment Be Sustained?, Russell Sage Foundation, New York.

[5] Bårdsen, G., E. Jansen, and R. Nymoen (2004): "Econometric evaluation of the new Keynesian Phillips curve", Oxford Bulletin of Economics and Statistics, 66, pp. 671-686.

[6] Blinder, A.S. and J.L. Yellen (2002): "The Fabulous Decade: Macroeconomic Lessons from the 1990s", The Century Foundation, New York.

[7] Calvo, G. A. (1983): "Staggered prices in a utility-maximizing framework", Journal of Monetary Economics, 12 (3), pp. 383-398.

[8] Christiano, L.J., Eichenbaum, M., and C.L. Evans (1999): "Monetary policy shocks: what have we learned and to what end?", in Handbook of Macroeconomics, Vol. 1A, M. Woodford and J. Taylor (Eds.), Elsevier Science, North-Holland, Amsterdam, New York and Oxford.

[9] Christiano, L.J., Eichenbaum, M., and C.L. Evans (2005): "Nominal rigidities and the dynamic effects of a shock to monetary policy", Journal of Political Economy, 113 (1), pp. 1-45.

[10] Cooley, T. F., and G. D. Hansen (1989): "The inflation tax in a real business cycle model", American Economic Review, 79 (4), pp. 733-748.

[11] Dedola, L., and F. Lippi (2005): "The monetary transmission mechanism: evidence from the industries of five OECD countries", European Economic Review, 49 (6), pp. 1543-1569. 
[12] Dolado, J.J., J.D. López-Salido and J.L. Vega (2000): "Unemployment and inflation persistence in Spain: are there Phillips tradeoffs?", Spanish Economic Review, 2, 267-291.

[13] Fisher, M.E. and J.J. Seater (1993): "Long-run neutrality and supeneutrality in an ARIMA framework", American Economic Review, 83, pp. 402-415.

[14] Fuhrer, J.C. (1995): "The Phillips curve is alive and well", New England Economic Review, Federal Reserve Bank of Boston, March/April, pp. 41-56.

[15] Galí, J. and M. Gertler (1999): "Inflation dynamics: a structural econometric analysis", Journal of Monetary Economics, 44, pp. 195-222.

[16] Goodfriend, M. and R.G. King (1997): "The new neoclassical synthesis and the role of monetary policy," NBER Macroeconomics Annual, pp. 231-295.

[17] Graham, L. and D.J. Snower (2008): "Hyperbolic discounting and the Phillips curve", Journal of Money, Credit and Banking, 40 (2-3), pp. 427-448.

[18] Grubb D., R. Jackman and R. Layard (1982): "Causes of the current stagflation," Review of Economic Studies, 49 (5), pp. 707-730.

[19] Hatton, T.J. (2007): "Can productivity growth explain the NAIRU? Long-run evidence from Britain, 1871-1999", Economica, 74 (295), pp. 475-491.

[20] Helpman, E. and L. Leiderman (1990): "Real wages, monetary accommodation, and inflation", European Economic Review, 34, pp. 897-911.

[21] Huang, K.X.D. and Z. Liu (2002): "Staggered price-setting, staggered wage-setting and business cycle persistence", Journal of Monetary Economics, 49, pp. 405-433.

[22] Ihrig, J. and J. Márquez (2004): "An empirical analysis of inflation in OECD Countries", International Finance, 7(1), pp. 61-84.

[23] Jaeger, A. and M. Parkinson (1994): "Some evidence on Hysteresis in unemployment rates", European Economic Review, 38, p. 329-342.

[24] Karanassou, M., H. Sala and P.F. Salvador (2008): "Capital Accumulation and Unemployment: New Insights on the Nordic Experience", Cambridge Journal of Economics, 32 (6), pp. 977-1001.

[25] Karanassou M., and H. Sala (2009): "The US Inflation-Unemployment Tradeoff: Methodological Issues and Further Evidence", IZA Discussion Paper No. 4252, Bonn.

[26] Karanassou, M., H. Sala and D.J. Snower (2005): "A reappraisal of the inflationunemployment tradeoff", European Journal of Political Economy, 21 (1), pp. 1-32.

[27] Karanassou, M., H. Sala and D.J. Snower (2008): "Long-run inflation-unemployment dynamics: The Spanish Phillips curve and economic policy", Journal of Policy Modeling, 30 (2), pp. 279-300.

[28] Karanassou M., H. Sala and D.J. Snower (2009): "Phillips curves and unemployment dynamics: a critique and a holistic perspective", Journal of Economic Surveys, forthcoming.

[29] Karanassou, M. and D.J. Snower (2008): "Inflation persistence and the Phillips curve revisited", mimeo.

[30] Leeper, E. M., Sims A., and T. Zha (1996): "What does monetary policy do?", Brookings Papers on Economic Activity, 2:1996, pp. 1-78. 
[31] Mankiw, N.G. (2001): "The inexorable and mysterious tradeoff between inflation and unemployment", The Economic Journal, 111, pp. C45-C61.

[32] Mankiw, N.G. and R. Reis (2002): "Sticky information versus sticky prices: a proposal to replace the New Keynesian Phillips curve", The Quarterly Journal of Economics, 117(4), pp. $1295-1328$.

[33] Mishkin, F.S. (2007a): "Monetary policy strategy: how did we get here?" in Mishkin, F.S. (Ed.), Monetary Policy Strategy, MIT Press, chapter 1: pp. 1-28.

[34] Mishkin, F.S. (2007b): "Inflation Dynamics", NBER Working Paper No. 13147.

[35] Nelson, E. (2007): "Comment on Samuel Reynard <Maintaining low inflation: money, interest rates, and policy stance>", Journal of Monetary Economics, 54(5), pp. 1472-79.

[36] Pesaran, M.H. and Y. Shin (1999): "An Autoregressive Distributed-Lag modelling approach to cointegration analysis" in Econometrics and Economic Theory in the Twentieth Century: The Ragnar Frisch Centennial Symposium, edited by Strom, S., Cambridge University Press, pp. 371-413.

[37] Pesaran, M.H., Shin, Y. and Smith, R.J. (2001): "Bounds testing approaches to the analysis of level relationships", Journal of Applied Econometrics, 16, pp. 289-326.

[38] Phelps, E. S. (1978): "Disinflation without Recession: Adaptive Guideposts and Monetary Policy", Weltwirtschaftliches Archiv, C, pp. 239-265.

[39] Raddatz, C., and R. Rigobon (2003): "Monetary policy and sectoral shocks: did the Fed react properly to the high-tech crisis?" NBER Working Paper, 9835.

[40] Roberts, J.M. (1995): "New Keynesian Economics and the Phillips curve", Journal of Money, Credit and Banking, 27 (4,1), pp. 975-984.

[41] Reynard, S. (2007): "Maintaining low inflation: money, interest rates, and policy stance", Journal of Monetary Economics, 54(5), pp. 1441-1471.

[42] Ribba, A. (2007): "Permanent disinflationary effects on unemployment in a small open economy: Italy 1979-1995", Economic Modelling, 24, pp. 66-81.

[43] Romer C.D, and D.H. Romer (2003): "Choosing the Federal Reserve chair: lessons from history," NBER Working Paper No. 10161.

[44] Rudebusch, G.D. (1998): "Do measures of monetary policy in a Var make sense?", International Economic Review, 39 (4), pp. 907-931.

[45] Staiger, D., J. Stock and M. Watson (2002): "Prices, wages and the U.S. NAIRU in the 1990s", in A. Krueger and R. Solow (eds.), The Roaring Nineties: Can Full Employment Be Sustained?, Russell Sage Foundation, New York.

[46] Stiglitz, J.E. (2003): The Roaring Nineties, W.W. Norton \& Company, New York.

[47] Taylor, J.B. (1979), "Staggered wage setting in a macro model," American Economic Review, 69, pp. 108-113.

[48] Taylor, J.B. (1980): "Aggregate dynamics and staggered contracts," Journal of Political Economy, 88 (1), pp. 1-23. 


\section{Appendix}

The estimated equations pass the standard misspecification tests for no serial correlation (SC), linearity (LIN), normality (NOR), heteroskedasticity (HET) and conditional heteroskedasticity (ARCH). The estimated parameters are structurally stable according to the CUSUM and CUSUM of squares $\left(\mathrm{CUSUM}^{2}\right)$ tests evaluated at the conventional significance levels.

\begin{tabular}{|c|c|c|c|c|}
\hline Equation: & $P$ & $W$ & $u$ & $\Delta k$ \\
\hline \multicolumn{5}{|c|}{ Misspecification tests: } \\
\hline $\mathrm{SC}$ & $0.02[0.890]$ & $0.05[0.828]$ & $0.05[0.822]$ & $0.23[0.635]$ \\
\hline LIN & $1.02[0.314]$ & $0.23[0.631]$ & $0.70[0.402]$ & $0.12[0.727]$ \\
\hline NOR & $0.97[0.617]$ & $0.05[0.977]$ & $0.20[0.903]$ & $0.26[0.880]$ \\
\hline HET & $1.83[0.118]$ & $0.56[0.783]$ & $1.38[0.255]$ & $1.43[0.239]$ \\
\hline $\mathrm{ARCH}$ & $0.10[0.750]$ & $3.17[0.075]$ & $0.21[0.650]$ & $2.49[0.114]$ \\
\hline \multicolumn{5}{|c|}{ Structural stability tests: } \\
\hline CUSUM & $\checkmark$ & $\checkmark$ & $\checkmark$ & $\checkmark$ \\
\hline CUSUM $^{2}$ & $\checkmark$ & $\checkmark$ & $\checkmark$ & $\checkmark$ \\
\hline
\end{tabular}

